\title{
Analisa Pola Perjalanan dan Karakteristik Penumpang Bus Trans Sidoarjo
}

\author{
Achmad Faiz Hadi Prayitno, ${ }^{1, *}$, Machsus ${ }^{1, *}$, Rachmad Basuki ${ }^{1}$, Sulchan Arifin ${ }^{1}$, Sukobar $^{1}$, Triaswati \\ Moeljono ${ }^{1}$, Wahyu Satyaning Budhi ${ }^{1}$ \\ Departemen Teknik Infrastruktur Sipil, Institut Teknologi Sepuluh Nopember, Kampus ITS, Surabaya ${ }^{1}$ \\ Koresponden*, Email: afaizhp@gmail.com
}

\begin{tabular}{ll}
\hline \multicolumn{1}{c}{ Info Artikel } & Abstract \\
\hline Diajukan 01 Pebruari 2018 & The Bus Trans Sidoarjo (BTS) operates to facilitate the movement of the population from \\
Diperbaiki 28 Maret 2018 & Sidoarjo to Surabaya and the opposite route. In this paper will be analyzed the travel patterns \\
Disetujui 27 Juli 2018 & and passenger characteristics of the BTS Route of Porong - Purabaya Terminal. The method \\
used includes analysis of passenger travel distribution, accessibility, average travel time and & headway, and operational cost. The result showed the highest passenger traffic patterns is \\
& between Pondok Mutiara Shelter - Purabaya Bus Station and Purabaya Bus Station - Pondok \\
& Jati Shelter. The characteristic dominant by female, age 40-44 years old, private employees, \\
the purpose to work, the way to the shelter and final destination use public transport and & delivered, origin and destination shelter by Purabaya Bus Station, fare by 6.000 rupiahs, \\
Keywords: bus trans sidoarjo, traffic & intensity by indefinitely. Average travel time is 59,53 minutes. Average headway is 29,92 \\
pattern, passenger characteristic, travel & minutes. Fares to use BTS is 6.000 rupiahs and 2.000 rupiahs, for private transport is 37.030 \\
time, headway. & -39.255 rupiahs /vehicle-km.
\end{tabular}

\begin{abstract}
Abstrak
Bus Trans Sidoarjo (BTS) dioperasikan untuk memperlancar pergerakan penduduk dari Sidoarjo ke Surabaya dan rute sebaliknya. Pada makalah ini akan dianalisa pola perjalanan dan karakteristik penumpang BTS Trayek Terminal Porong - Purabaya. Metode yang digunakan meliputi analisa distribusi perjalanan penumpang, aksesibiltas, waktu tempuh rata-rata dan headway, serta analisa biaya operasional kendaraan (BOK). Hasil analisa menunjukkan pola perjalanan penumpang terbanyak yaitu antar Halte Pondok Mutiara - Terminal Purabaya dan antar Terminal Purabaya - Pondok Jati. Karakteristik penumpang didominasi perempuan, umur 40-44 tahun, pekerjaan pegawai swasta, maksud perjalanan bekerja, cara menuju halte dan tempat tujuan akhir menggunakan angkutan kota dan diantar, halte asal dan tujuan Terminal Purabaya, tarif 6.000 rupiah, serta intensitas secara tak tentu. Waktu tempuh rata-rata 59,53 menit. Headway rata-rata 29,92 menit. Tarif untuk BTS sebesar 6.000 rupiah dan 2.000 rupiah, sedangkan untuk kendaraan pribadi sebesar 37.030 rupiah - $39.255 \mathrm{rupiah} / \mathrm{kendaraan}-\mathrm{km}$.
\end{abstract}

perjalanan, karakteristik penumpang, waktu tempuh, headway.
Kabupaten Sidoarjo dengan 16 pemberhentian bus atau shelter bus di beberapa titik, yang mana trayek bus dimulai dari Terminal Porong hingga Terminal Purabaya[7].

BTS diharapkan mampu meningkatkan minat masyarakat untuk menggunakan transportasi umum. Namun, permasalahan yang ada sekarang adalah masyarakat masih memilih untuk menggunakan transportasi pribadi. Layanan BTS masih belum mampu memenuhi kebutuhan penumpang, terkait dengan aksesibilitas, rute, waktu tempuh dan headway[8],[9].

Dengan demikian, perlu adanya analisa dalam pola perjalanan dan karakteristik penumpang BTS, analisa waktu tempuh dan headway bus, dan analisa biaya operasional bus dan kendaraan pribadi. Hal ini dimaksudkan agar dapat tercipta moda transportasi yang lebih baik dan meningkatkan keinginan penumpang untuk lebih memilih moda transportasi massal[10]. 


\section{Metode}

Secara garis besar, tahapan dalam studi ini dibagi menjadi tahap pengumpulan data dan pengolahan, analisa dan pembahasan dan penarikan kesimpulan. Data sekunder dalam studi ini yaitu jumlah armada bus, peta rute bus, dan data jumlah penumpang. Sedangkan untuk data primer yang diperlukan yaitu, pola perjalanan penumpang, karakteristik penumpang, waktu antara (headway), waktu tempuh, dan waktu henti[4].

Survey waktu antara (headway) dilakukan di empat halte, pada jam $05.30 \mathrm{~s} / \mathrm{d} 19.30$, waktu diukur menggunakan stopwatch. Survey pola perjalanan dan karakteristik penumpang dilakukan diatas bus dengan cara membagikan kuesioner yang telah disiapkan untuk diisi oleh penumpang[11].

Tahapan analisa dan pembahasan dalam studi ini meliputi cek uji keseragaman sampel, analisa aksesibilitas, analisa distribusi perjalanan, analisa karakteristik penumpang, serta analisa biaya operasi kendaraan (BOK). Jika tahapan analisa dan pembahasan telah selesai maka dapat dilakukan penarikan kesimpulan[2].

\section{Hasil dan Pembahasan}

Hasil analisa Matriks Asal Tujuan (MAT) digambarkan dalam Garis Keinginan pada Gambar 1 dan Gambar 2.

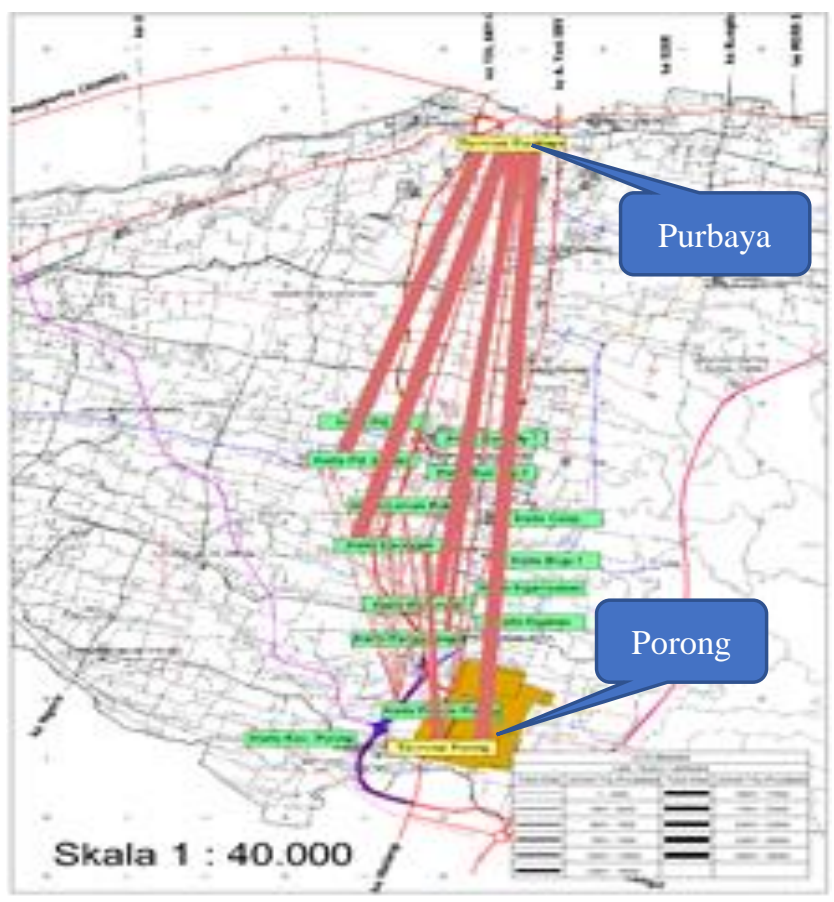

Gambar 1. Garis keinginan penumpang BTS rute Porong Purabaya pada 5 (lima) tahun mendatang

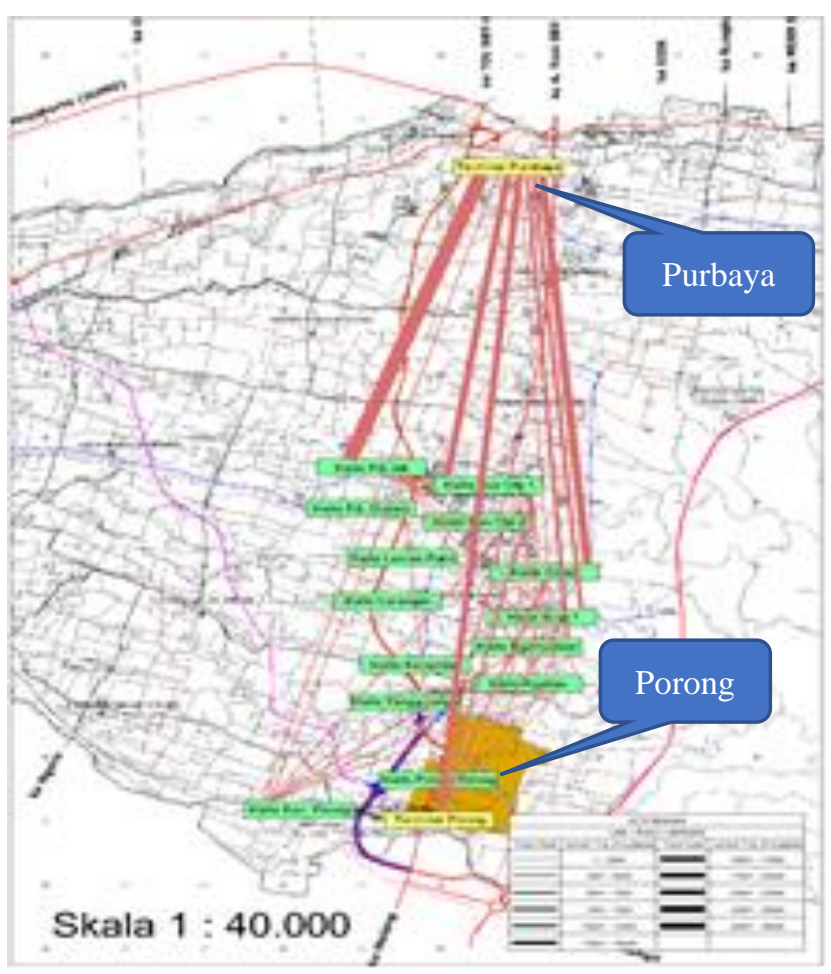

Gambar 2. Garis keinginan penumpang BTS rute Purabaya - Porong pada 5 (lima) tahun mendatang

Berdasarkan analisa Matriks Asal Tujuan (MAT), maka untuk rute Terminal Porong - Terminal Purabaya menunjukkan bahwa pola perjalanan penumpang paling banyak adalah yang berasal dari Halte Pondok Mutiara menuju ke Terminal Purabaya sebesar 27.913 penumpang/minggu. Sedangkan, untuk rute Terminal Purabaya - Terminal Porong bahwa pola perjalanan penumpang paling banyak adalah yang berasal dari Terminal Purabaya menuju ke Halte Pondok Jati sebesar 26.168 penumpang/minggu[4].

Berdasarkan analisa aksesibilitas didapatkan nilai aksesibilitas tertinggi untuk rute Terminal Porong - Terminal Purabaya yaitu antar Halte Lemah Putro dan Halte Sun City 2 dan nilai aksesibilitas terendah yaitu antar Halte Pd. Mutiara dan Terminal Purabaya. Sedangkan, pada rute Terminal Purabaya - Terminal Porong yaitu antar Halte Ngampelsari dan Halte Ngaban dan nilai aksesibilitas terendah yaitu antar Terminal Purabaya dan Halte Pd. Jati. Grafik total nilai aksesibilitas dapat dilihat pada Gambar 3 dan Gambar 4. 


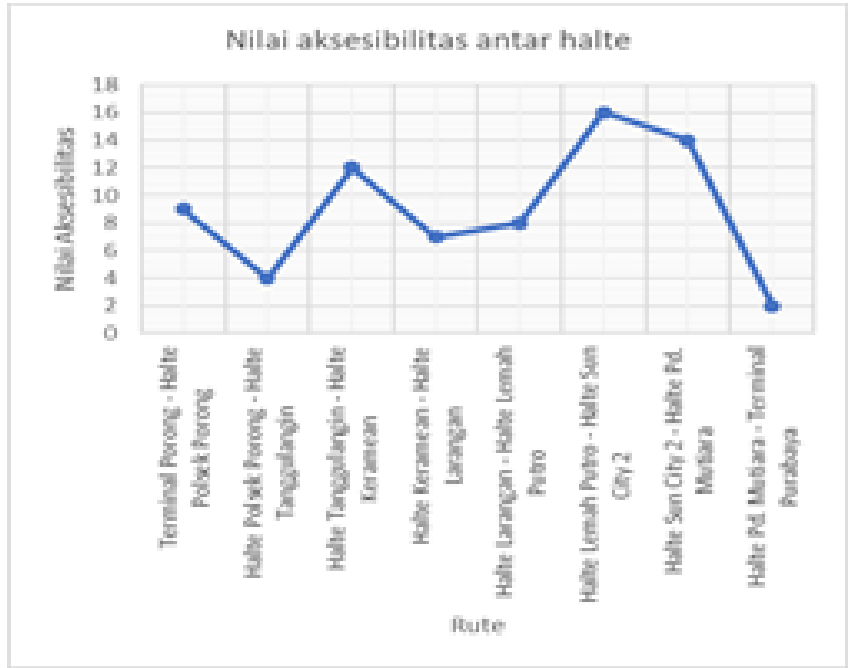

Gambar 3. Grafik total nilai aksesibilitas rute Terminal Porong - Terminal Purabaya

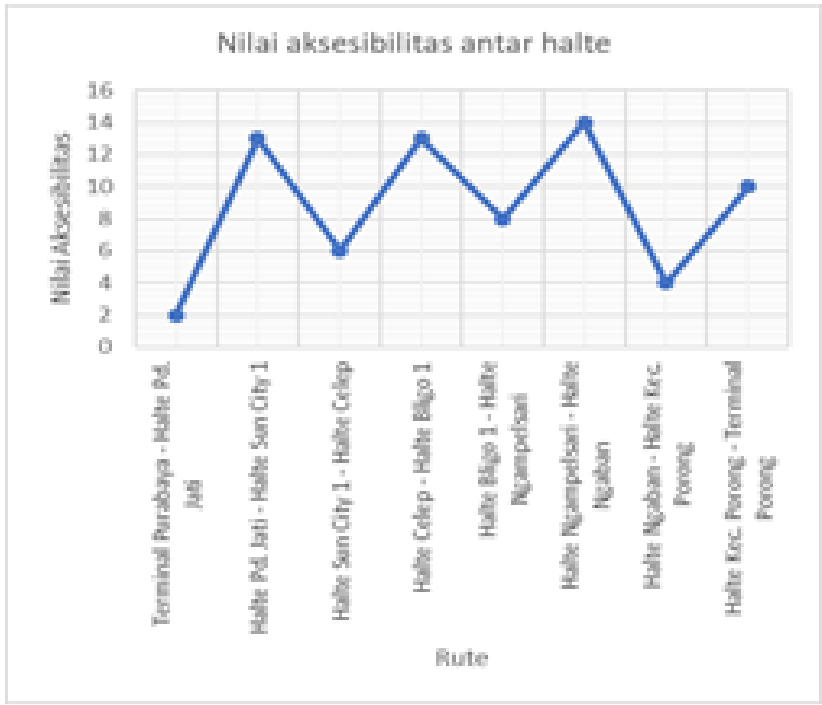

Gambar 4. Grafik total nilai aksesibilitas rute Terminal Purabaya - Terminal Porong

Karakteristik penumpang didapatkan melalui survey on bus dengan cara pengisian kuisioner oleh penumpang BTS. Penumpang dikelompokkan dan ditinjau berdasarkan umur, jenis kelamin, pekerjaan, tujuan perjalanan, tempat dan asal tujuan, waktu perjalanan, tarif atau biaya perjalanan dapat dilihat pada Gambar 5-16.

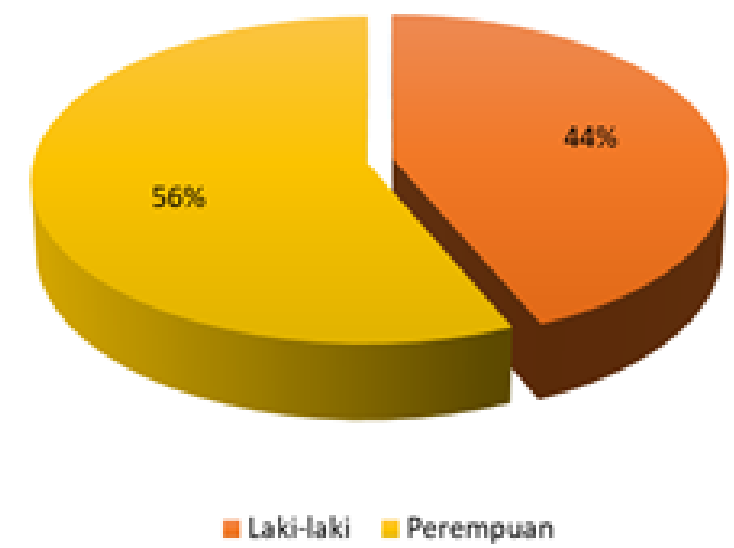

Gambar 5. Diagram karakteristik penumpang BTS berdasarkan jenis kelamin

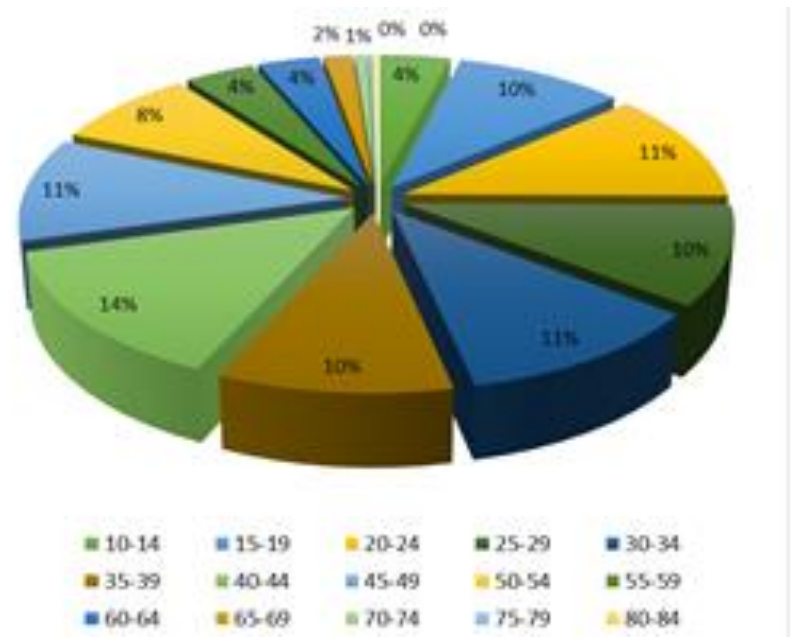

Gambar 6. Diagram karakteristik penumpang BTS berdasarkan umur

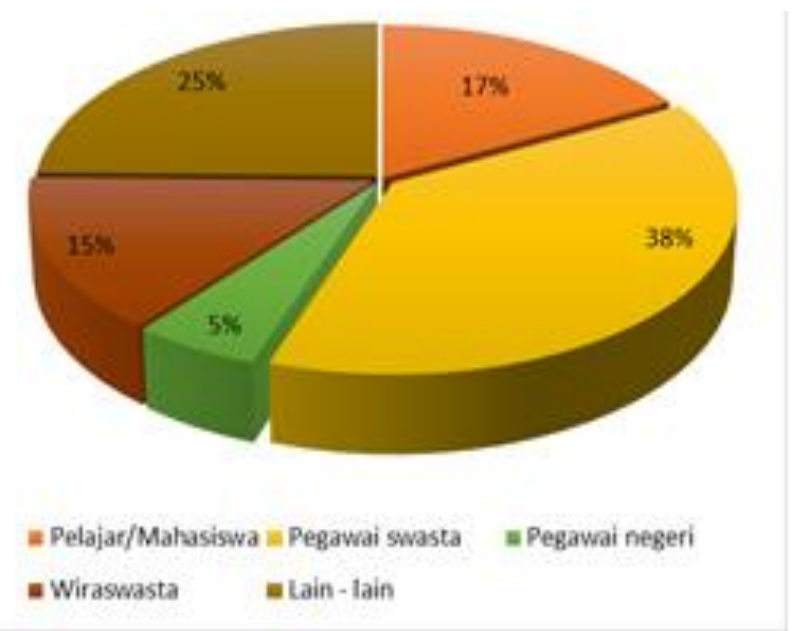

Gambar 7. Diagram karakteristik penumpang BTS berdasarkan pekerjaan 


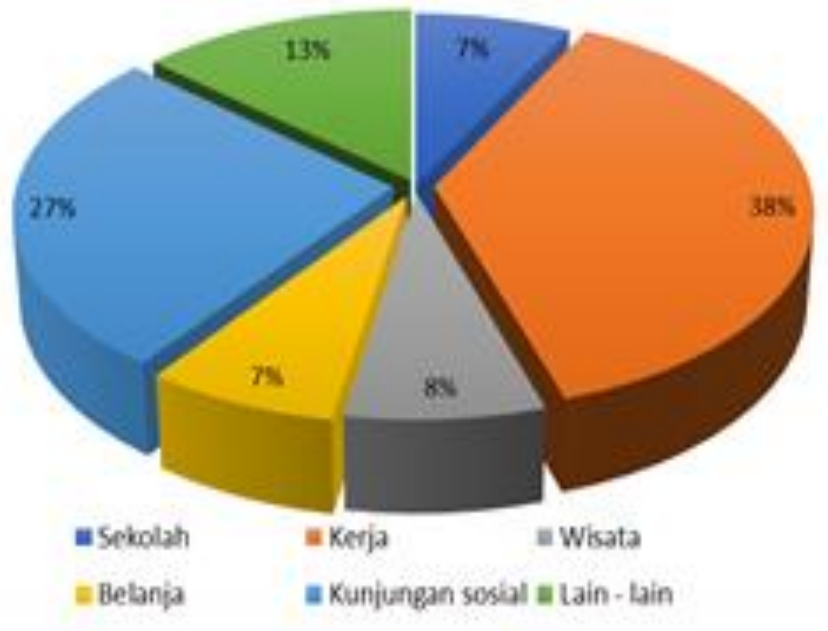

Gambar 8. Diagram karakteristik penumpang BTS berdasarkan maksud perjalanan

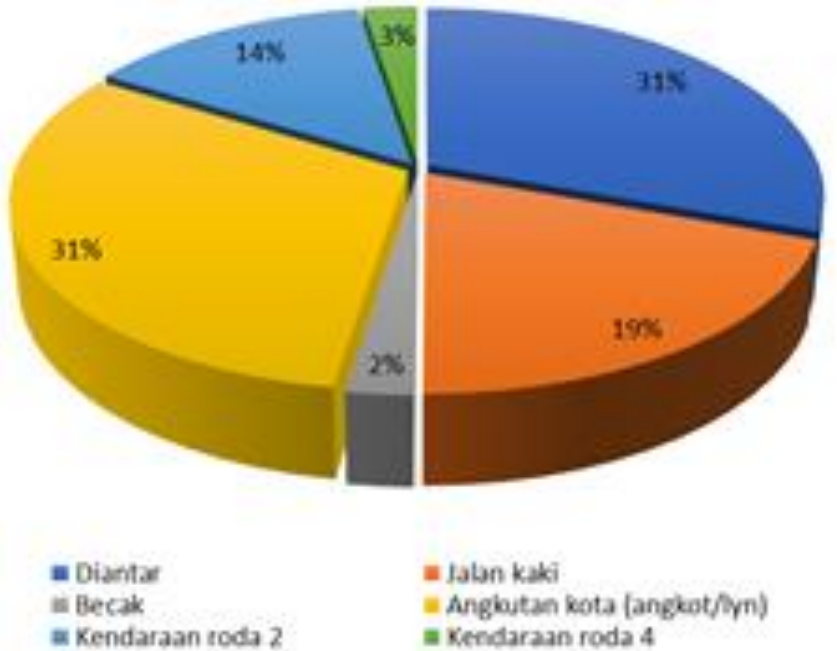

Gambar 9. Diagram karakteristik penumpang BTS berdasarkan cara menuju halte

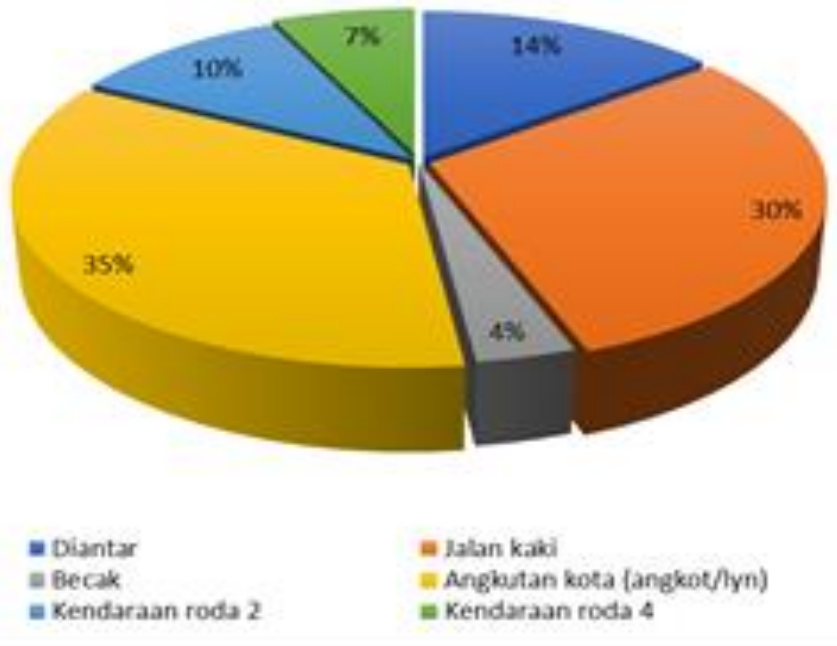

Gambar 10. Diagram karakteristik penumpang BTS berdasarkan cara menuju tempat tujuan

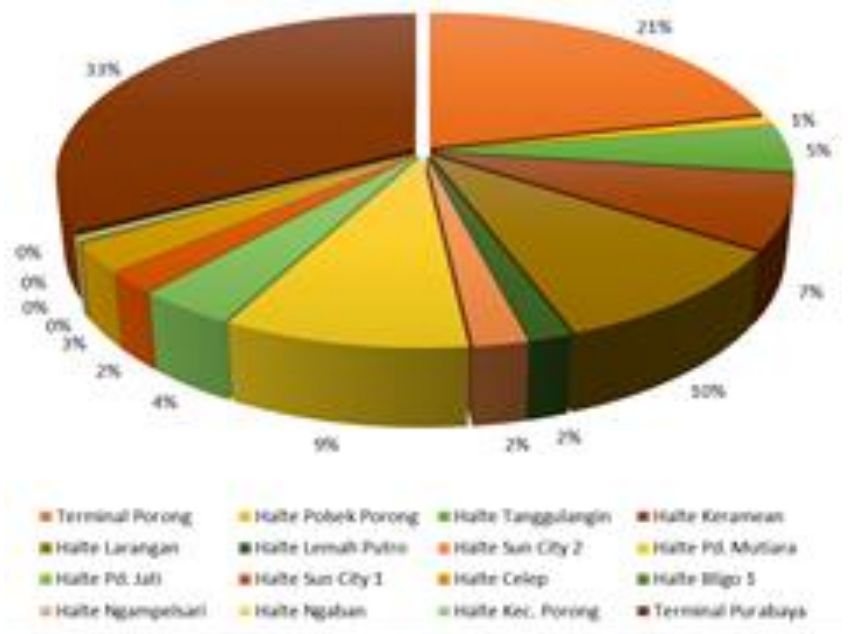

Gambar 11. Diagram karakteristik penumpang BTS berdasarkan halte asal

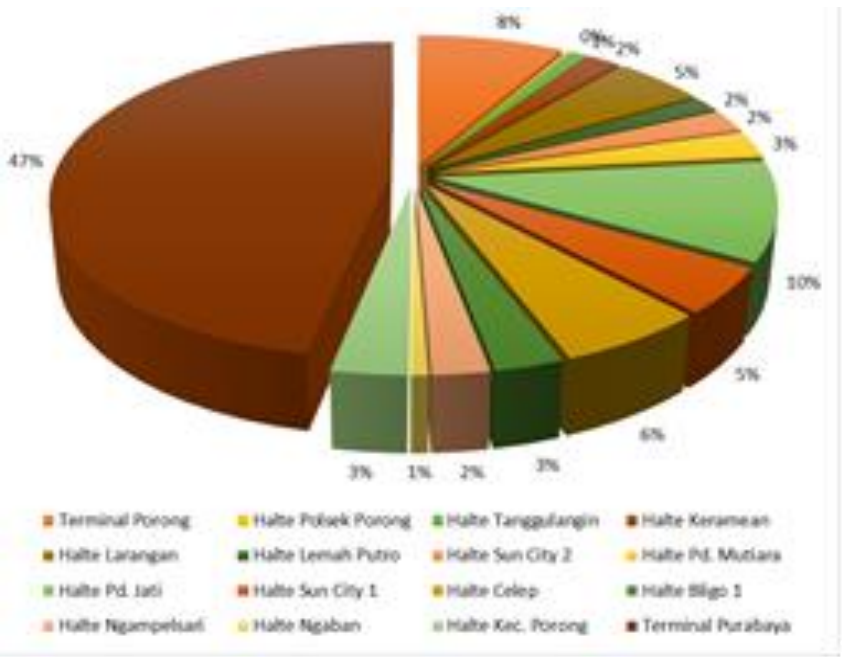

Gambar 12. Diagram karakteristik penumpang BTS berdasarkan halte tujuan

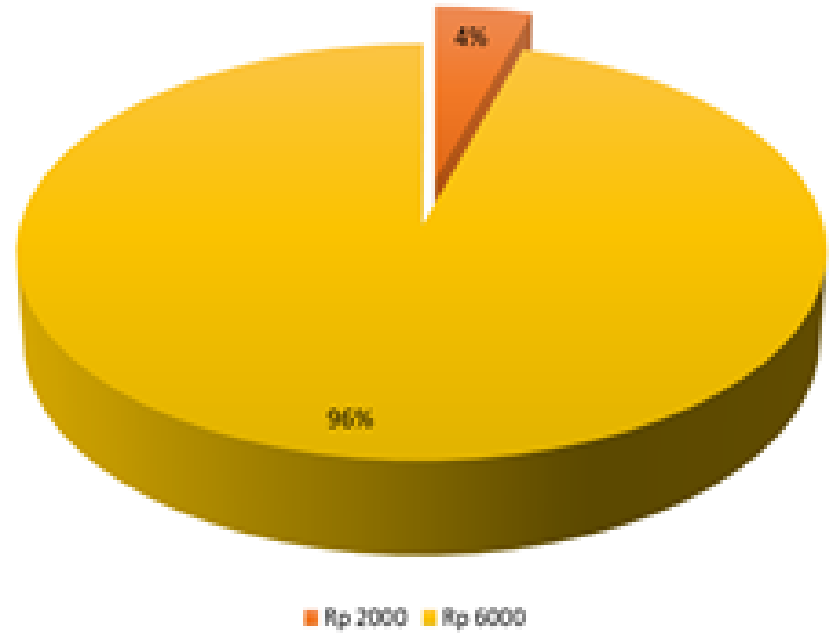

Gambar 13. Diagram karakteristik penumpang BTS berdasarkan tarif 


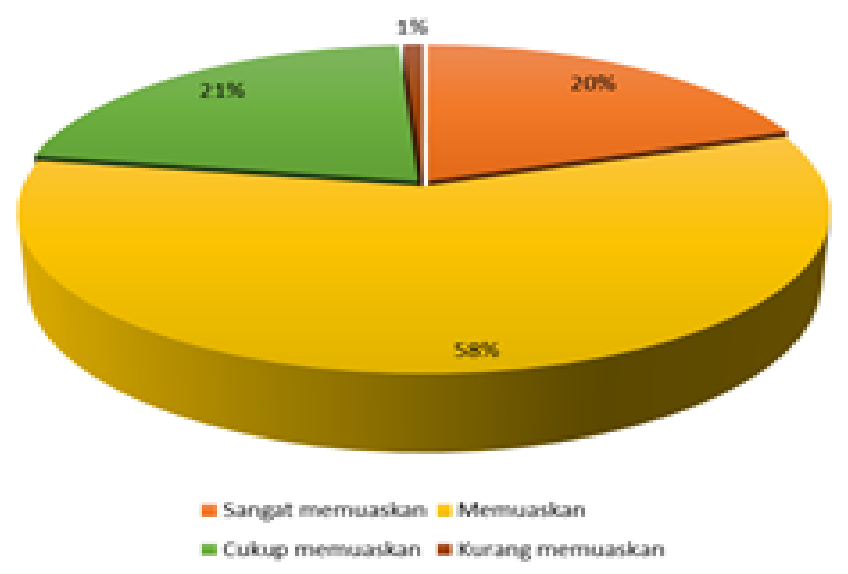

Gambar 14. Diagram tingkat pelayanan BTS menurut penumpang

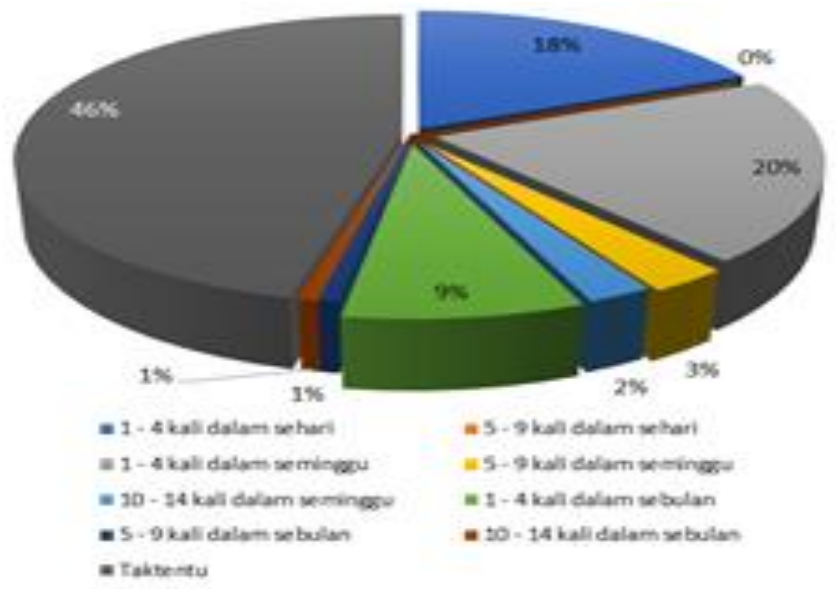

Gambar 15. Diagram karakteristik penumpang BTS intensitas penggunaan

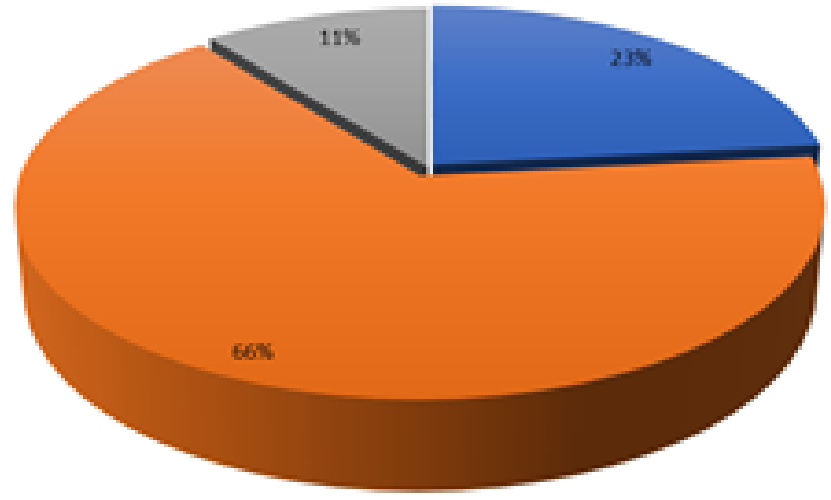

aebershan dan kenyamanan bus = Indormasi wattu kedatanean bus = Thiak merivimab

Gambar 16. Diagram saran penumpang BTS

Waktu tempuh rata-rata tersingkat untuk rute Terminal Porong - Purabaya adalah antara Halte Lemah Putro dengan Halte Sun City 2 sebesar 2,65 menit dan waktu tempuh terpanjang adalah antara Halte Pondok Mutiara dengan Terminal Purabaya sebesar 23,82 menit. Sedangkan, untuk rute Terminal Purabaya - Porong waktu tempuh rata-rata tersingkat adalah antara Halte Ngampelsari dengan Halte Ngaban sebesar 2,05 menit dan waktu tempuh terpanjang adalah antara Terminal Purabaya dengan Halte Pondok Jati sebesar 25,08 menit. Maka waktu tempuh rata-rata untuk satu rit perjalanan adalah sebesar 59,53 menit.

Kecepatan rata-rata tersingkat pada rute Terminal Porong - Purabaya adalah Halte Sun City 2 - Halte Pd. Mutiara sebesar $16,97 \mathrm{~km} / \mathrm{jam}$, sedangkan kecepatan rata-rata terbesar adalah antara Halte Pd. Mutiara - Terminal Purabaya sebesar $42,59 \mathrm{~km} / \mathrm{jam}$. Sedangkan kecepatan rata-rata bus tersingkat untuk rute Terminal Purabaya - Porong adalah antara Halte Kec. Porong - Terminal Porong sebesar 20,13 km/jam, dan Halte Ngaban - Halte Kec. Porong 43,83 km/jam. Sedangkan kecepatan rata-rata pada non tol BTS adalah sebesar 26,91 $\mathrm{km} / \mathrm{jam}$, dan untuk kecepatan rata-rata pada tol adalah sebesar 41,68 km/jam. Hasil survey waktu antara (headway) yang telah dianalisa dapat dilihat pada Tabel 1-4.

Berdasarkan hasil survey waktu antara (headway) tersebut, maka didapatkan headway rata - rata keseluruhan halte adalah sebesar 29,92 menit.

Tabel 1. Headway rata - rata pada Halte Pondok Jati

\begin{tabular}{ccc}
\hline Hari & Tanggal & Headway rata - rata \\
\hline Sabtu & 28 Oktober 2017 & 26 menit \\
Senin & 30 Oktober 2017 & 30 menit \\
Selasa & 31 Oktober 2017 & 35 menit \\
\hline
\end{tabular}

Tabel 2. Headway rata - rata pada Halte Sun City 1

\begin{tabular}{ccc}
\hline Hari & Tanggal & Headway rata - rata \\
\hline Sabtu & 28 Oktober 2017 & 26 menit \\
Senin & 30 Oktober 2017 & 30 menit \\
Selasa & 31 Oktober 2017 & 34 menit \\
\hline
\end{tabular}

Tabel 3. Headway rata - rata pada Halte Pondok Mutiara

\begin{tabular}{ccc}
\hline Hari & Tanggal & Headway rata - rata \\
\hline Sabtu & 28 Oktober 2017 & 27 menit \\
Senin & 30 Oktober 2017 & 29 menit \\
Selasa & 31 Oktober 2017 & 33 menit \\
\hline
\end{tabular}

Tabel 4. Headway rata - rata pada Halte Sun City 2

\begin{tabular}{ccc}
\hline Hari & Tanggal & Headway rata - rata \\
\hline Sabtu & 28 Oktober 2017 & 27 menit \\
Senin & 30 Oktober 2017 & 29 menit \\
Selasa & 31 Oktober 2017 & 33 menit \\
\hline
\end{tabular}




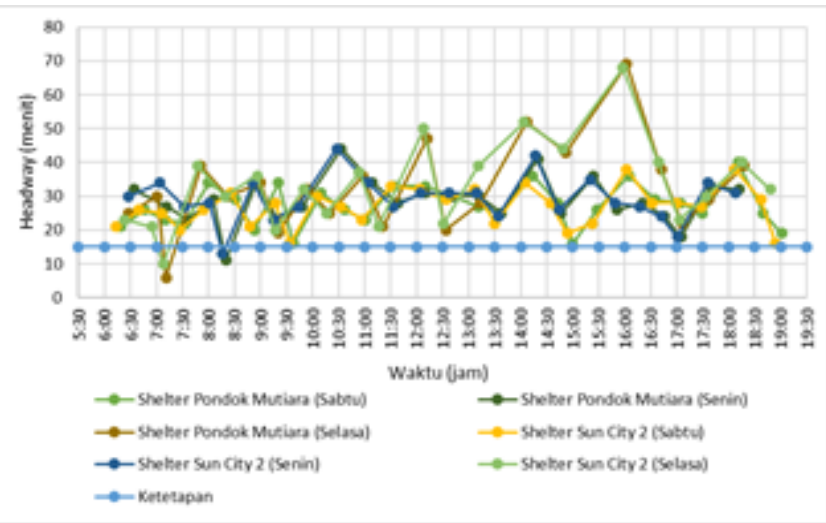

Gambar 17. Grafik headway rata-rata Trayek Terminal

Porong - Purabaya

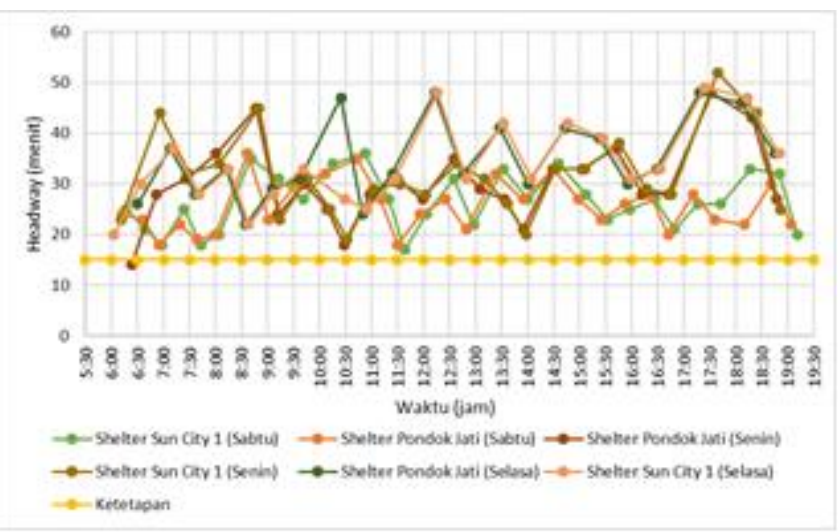

Gambar 18. Grafik headway rata-rata Trayek Terminal

Purabaya - Porong

Biaya yang dikenakan pada tiap penumpang untuk satu rit dengan menggunakan faktor muat (load factor) eksisting 24,23\% adalah sebesar Rp 25.477,00/penumpang, sedangkan menggunakan faktor muat Departemen Perhubungan Darat $70 \%$ biaya yang dikenakan adalah sebesar Rp 8.819,00/penumpang[12]. Namun tarif yang berlaku BTS pada tahun 2017 adalah seharga Rp 6.000,00 untuk penumpang umum/mahasiswa, dan Rp 2.000,00 untuk pelajar. Hal ini menunjukkan adanya subsidi dari pemerintah sebesar Rp 2.819,00/penumpang untuk penumpang umum/mahasiswa, dan $\mathrm{Rp}$ 6.819,00 untuk pelajar. Lain halnya dengan biaya operasional yang digunakan oleh kendaraan pribadi Golongan 1 dengan rute yang sama (per rit) sebagai pembanding, biaya yang harus dikeluarkan adalah sebesar Rp 37.030,00-Rp 39.255,00 dengan kecepatan $60 \mathrm{~km} / \mathrm{jam}$.

Nilai waktu dikaitkan dengan besarnya jumlah uang yang dikeluarkan pengguna moda transportasi untuk menghemat satu unit waktu perjalanan[10]. Nilai waktu yang diperlukan untuk menggunakan BTS dengan acuan PDRB harga konstan adalah sebesar Rp 26.570,00/orang/jam, sedangkan perhitungan dengan metode PCI menggunakan kendaraan pribadi kecepatan 30 km/jam adalah sebesar Rp 13.224,12 - Rp 14.104,07. Hal ini menunjukkan adanya selisih nilai waktu menggunakan bus dan kendaraan pribadi sebesar Rp $12.906,00$.

\section{Simpulan}

Dari hasil dan pembahasan dapat diambil beberapa kesimpulan sebagai berikut:

1. Pola perjalanan penumpang terbanyak untuk rute Terminal Porong - Terminal Purabaya yaitu antar Halte Pondok Mutiara - Terminal Purabaya sebesar 27.913 penumpang, untuk rute sebaliknya yaitu antar Terminal Purabaya - Pondok Jati sebesar 26.168 Penumpang. Nilai aksesibilitas tertinggi untuk rute Terminal Porong - Terminal Purabaya adalah antara Halte Lemah Puto Halte Sun City 2 dengan nilai 16, sedangkan untuk rute sebaliknya adalahantar Halte Ngampelsari - Halte Ngaban dengan nilai 14 .

2. Berdasarkan karakteristik, jenis kelamin dominan adalah perempuan sebesar 56\%, umur dominan 40-44 tahun sebesar 13,9\%, pekerjaan dominan pegawai swasta sebesar 38\%, maksud perjalanan dominan adalah bekerja sebesar $38 \%$, cara menuju halte didominasi menggunakan angkutan kota dan diantar sebesar $31 \%$, cara menuju tempat tujuan akhir didominasi angkutan kota dan diantar sebesar $35 \%$, halte asal didominasi Terminal Purabaya sebesar 32\%, halte tujuan didominasi Terminal Purabaya sebesar $47 \%$, tarif didominasi dengan tarif 6.000 rupiah sebesar 96\%, intensitas didominasi secara tak tentu sebesar $46 \%$.

3. Waktu tempuh terpanjang yaitu antar halte Halte Pondok Mutiara - Terminal Purabaya sebesar 23,7 menit untuk rute Terminal Porong - Terminal Purabaya, untuk rute sebaliknya yaitu antar Terminal Purabaya - Halte Pondok Jati sebesar 25,3 menit. Waktu tempuh rata-rata untuk satu rit perjalanan adalah sebesar 59,53 menit.

4. Berdasarkan survey yang dilakukan, headway rata - rata keseluruhan halte adalah sebesar 29,92 menit.

5. Tarif yang diperlukan untuk menggunakan BTS yaitu sebesar Rp 6.000,00 (umum/mahasiswa) dan Rp 2.000,00 (pelajar), sedangkan untuk kendaraan pribadi membutuhkan biaya sebesar Rp 37.030,00 - Rp $39.255,00$

\section{Daftar Pustaka}

[1] R. Indonesia, "UU Nomor 22 Tahun 2009 Tentang Lalu Lintas dan Angkutan Jalan,” p. 209, 2009.

[2] M. Machsus, "Analisa Kinerja Pelayanan Angkutan Umum Perkotaan," in Prosiding Seminar Nasional Forum Pendidikan Tinggi Vokasi Indonesia, 2017, pp. 438-451.

[3] R. Indonesia, "Peraturan Pemerintah No 41 tentang Angkutan," 1993. 
[4] S. P. (Suwardjoko P. Warpani, Pengelolaan lalu lintas dan angkutan jalan. Penerbit ITB, 2002.

[5] M. Machsus and R. Basuki, "Penggunaan BBG pada Kendaraan Bermotor di Kota Surabaya," J. Apl. Tek. Sipil, vol. 4, no. 1, pp. 34-42, Feb. 2008.

[6] Kementerian PU, "Pedoman Kapasitas Jalan Perkotaan," 2014.

[7] I. Sholichin, "Analisa Kepuasan Penumpang Angkutan Kota terhadap Sistem Pelayanan Angkutan Kota di Kota Sidoarjo," J. Apl. Tek. Sipil, vol. 8, pp. $1-8,2010$.

[8] A. F. H. P, "Analisa Model Gravity dan Analogi Fluida padaTrip Distribusi Penumpang Angkutan Kota Trayek Terminal Bratang - JMP Surabaya," $J$. Apl. Tek. Sipil, vol. 2, pp. 31-39, 2007.

[9] A. F. H. P, "Evaluasi Kinerja Angkutan Kota Lyn T2 Jurusan Terminal Joyoboyo - Wisma Permai Surabaya," J. Apl. Tek. Sipil, vol. 9, pp. 34-50, 2015.

[10] H. Faiz, "Studi Kemampuan dan Kemauan Membayar Konsumen Jasa Angkutan Umum Bus Damri Ekonomi di Kota Surabaya," J. Apl. Tek. Sipil, vol. 1, pp. 11-17, 2008.

[11] Kementerian PU, "Pedoman Teknis Halte," no. Pedoman Teknis Halte, pp. 0-3, 2012.

[12] M. N. Faadhilah, "Analisa Penerapan Bus Feeder Brt pada Kawasan Pondok Gede Bekasi sebagai Solusi Mengurangi Kemacetan,” 2017. 
